\title{
Profile of occupational accidents reporting to a rural Plantation Hospital: A record review
}

\begin{abstract}
:
Background: Plantation industries in India employ over 1 million people and are among the largest private employers in India. Plantations employ both skilled and un-skilled labour's. The risks of occupational accidents are higher among this population due to the unfavorable working conditions. Objectives: To study the profile of occupational accidents and to describe the time trend of these occupational accidents. To assess changes if any in the profile of occupational accidents reporting to a rural plantation hospital over the last decade. Methodology: A descriptive hospital record review of all the patients presenting with occupational accident from January 2008 to December 2009. Results: 439 patients were registered with history of accidents; among them 196 were occupational accidents. Majority of the victims of the accident were in the age group of 21-40 years and were among males. Most common type and site of injuries were superficial injuries on the upper limbs. There is no significant change in the profile on occupational accidents over the last decade.
\end{abstract}

Key Words: Occupational accidents; plantations; rural; hospital

Naveen $\mathrm{R}^{\#}$, Swaroop $\mathrm{N}^{@}$, Suyash Agrawal $^{\#}$, Anup Kumar Tirkey ${ }^{\#}$

"Department of Community Health

St. John's Medical College and Hospital

@St. John’s Research Institute

Corresponding Author: Dr. Naveen $\mathbf{R}$

Email: drnaveenr@gmail.com

๑) 2013 IJOSH All rights reserved.

DOI: http://dx.doi.org/10.3126/ijosh.v3i2.6138

\section{Introduction}

Plantation industries in India employ over 1 million people and are among the largest private employers in India. The Plantation workforce, are among the most exploited workforce in the organized sector - low wages, working and living conditions are poor, work in remote and isolated areas and are illiterate and or migrants with no awareness or information about their rights [1]. India accounts for about $4.5 \%$ of world coffee production and is one of the largest tea producer and consumer in the world. Coffee is grown mainly in the three South Indian states namely Karnataka, Tamil Nadu and Kerala and tea is grown predominantly in the North Eastern part of India and South India $[2,3]$.

The unfavorable working conditions and/or negligence among the workers, contributes to the risk of occupational accidents [4]. According to the ILO, an occupational accident is an unexpected and unplanned occurrence, including acts of violence, arising out of or in connection with work, which results in one or more workers incurring a personal injury, disease or death [5]. The rates are different for individual countries and regions and for separate branches of economic activity. In 1994, the global fatal occupational accident was reported to be fourteen per one lakh workers [6]. Although the profile of the at-risk worker population has changed greatly over the past decade, both quantitatively and qualitatively, the risk of occupational accident still centers on workers of various industries [7]. This study was done to assess if there were any changes in the profile of occupational accidents over the last decade compared to a study done in the same setting which had reported that occupational accidents contributed the most to the accidents reporting to the hospital [8]. Few studies have been published regarding occupational accidents occurring among Indian plantation workers. Studies of this nature helps in developing appropriate preventive strategies.

1. To study the profile of occupational accidents reporting to a rural plantation hospital and to describe the time trend of these occupational accidents.

2. To assess changes if any in the profile of occupational accidents reporting to a rural plantation hospital over the last decade.

\section{Methods}

This was a descriptive hospital based record review which included all the patients presenting to secondary level referral plantation hospital with an occupational accident from January, 2008 to December, 2009. The data was collected from the Medical Records Department of the rural plantation hospital. Data was entered in the excel spread sheet and analysis was done using standard statistical software. Frequencies were calculated for categorical variables. Chi-square $\left(\chi^{2}\right)$ and Fisher's 
exact tests were used to study association of occupational accidents with basic demographic characters. A 'p' value of less than 0.05 was considered to be statistically significant for all analyses.

\section{Results}

A total number of 439 patients presented to the rural plantation hospital with the history of accidents from 1st January 2008 to 31st December 2009. Among the 439 accidents reported, 196 were occupation related accidents. This study describes the 196 occupational accidents presenting to the hospital. The accidents have been described in terms of the type of accident, the type of injury and the part of body injured in accordance to the International Labour Organization guidelines [9, 10].

\section{Demographic profile}

Majority i.e. $66.3 \%$ of the study population were in the age group of 21 - $40 \mathrm{yrs}$ as depicted in Table I The mean age was found to be $34.13 \pm 11.79$ years with a range of $11-70$ years. Gender wise analysis indicates that majority of the occupational accidents occurred among males accounting for $62.8 \%$.

\section{Description of occupational accidents}

Forty eight percent of the occupational accidents occurred between April and July followed by $12.2 \%$ in February and $8.7 \%$ in November.

On analysis of the distribution of all the types of accident, falls were the most common type (45.9\%), followed by cut injuries (24.3\%) as described in Table II Information regarding the type of accident was missing in the records of two people. There was no significant difference between the type of accident and age $\left(\chi^{2}=0.37, \mathrm{df}=1\right.$, ' $p$ ' value $\left.=0.88\right)$, gender of the patient $\left(\chi^{2}=2.31, \mathrm{df}=1\right.$, ' $p$ ' value $\left.=0.085\right)$.

\section{Table I Age distribution of the study population}

\begin{tabular}{|c|c|c|}
\hline Age (in years) & No. of people & Percentage (\%) \\
\hline $11-20$ & 19 & 9.7 \\
\hline $21-30$ & 73 & 37.2 \\
\hline $31-40$ & 57 & 29.1 \\
\hline $41-50$ & 28 & 14.3 \\
\hline $51-60$ & 13 & 6.6 \\
\hline$>60$ & 6 & 3.1 \\
\hline Total & 196 & 100.0 \\
\hline
\end{tabular}

When the data was analysed according to the type of injuries it was found that $80.1 \%$ of the accidents resulted in superficial injuries or open lacerated wounds followed by fractures which accounted $17.8 \%$ of the total injuries. Contusion and burns comprised of $1.6 \%$ and $0.5 \%$ respectively, Table III. Data regarding type of injuries was lacking in five records.

On analysis of accidents according to the site involved, it was found that limbs were affected in $70.1 \%$ of the cases and upper limbs were more commonly involved (35.2\%) compared to lower limbs (25.9\%). Head injury was seen in $14 \%$ of the cases and trunk was affected in $10.4 \%$ of the cases (Table IV). Data regarding site of injury was not available for three people.

Table II Distribution of accidents according to type of accident

\begin{tabular}{|c|c|c|}
\hline Type of accident & No. of people & Percentage (\%) \\
\hline Fall on the same level & 89 & 45.8 \\
\hline Occupational Cut Injury & 47 & 24.2 \\
\hline Fall from height & 17 & 8.8 \\
\hline Animal Bite & 12 & 6.2 \\
\hline Struck by moving object & 16 & 8.2 \\
\hline Stepping on objects & 7 & 3.6 \\
\hline Animal Attack & 3 & 1.5 \\
\hline Exposure to electric current & 2 & 1.0 \\
\hline Bullet Injury & 1 & 0.5 \\
\hline Total & 194 & 100.0 \\
\hline
\end{tabular}

Table III Distribution of accidents according to type of injury

\begin{tabular}{|c|c|c|}
\hline Type of Injury & No. of people & Percentage (\%) \\
\hline Superficial injury & 153 & 80.1 \\
\hline Fracture & 34 & 17.8 \\
\hline Concussion and internal injury & 3 & 1.6 \\
\hline Burns & 1 & 0.5 \\
\hline Total & 191 & 100.0 \\
\hline
\end{tabular}

\section{Discussion}

Plantation is a place where workers work at high altitude, sloped, uneven terrain and extremes of temperature along with the use of hazardous agro-chemicals like pesticides, fertilizers, etc. These conditions put the workers at equal risk of being injured when compared to workers in other sectors [4].

Table IV Distribution of accidents according to part of body injured

\begin{tabular}{|c|c|c|}
\hline Site of Injury & No. of people & Percentage (\%) \\
\hline Upper limbs & 68 & 35.2 \\
\hline Lower limbs & 50 & 25.9 \\
\hline Head & 27 & 14.0 \\
\hline Abdomen and internal organs & 20 & 10.4 \\
\hline Spinal cord and vertebrae & 18 & 9.3 \\
\hline Multiple injuries & 10 & 5.2 \\
\hline Total & 193 & 100.0 \\
\hline
\end{tabular}

Total of 27,331 people utilized the facilities of the hospital during the study period. The total number of occupational accidents was $44.6 \%$ of the total number of accidents cases presenting to the hospital. This is higher compared to the previous study findings of $42.09 \%$ which was done in the same hospital [6]. The 
maximum number of occupational accidents i.e. $66.3 \%$ occurred in the age group of $21-40$ years which is similar compared to the previous study done in the same hospital [8]. More than a third of the occupational accidents occurred in the most economically productive age group of 21 to 50 years which could affect the socioeconomic status of the individuals and their families. Also the occurrence of accidents decreased with increasing age, which could be due to increased work experience on the plantations.

Figure 1. Distribution of occupational accidents according to the month

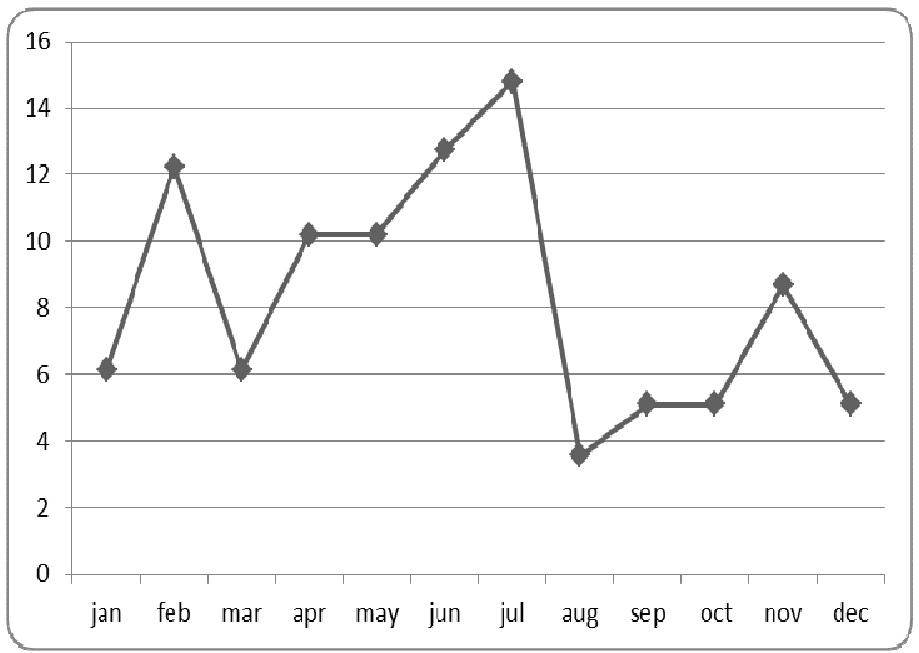

As much as $48 \%$ of the accidents reported to the hospital between April to July, which coincides with the "peak season" for harvesting pepper and another important activity during this season is shade lopping. During this season the payment to the workers is based on the number of kilograms of pepper picked per day. Both the local population and the migrant workers from the plains who have little or no experience of working in plantations are involved in picking pepper and in shade lopping activities. The use of "bamboo poles" as ladders placed on an uneven and slippery (due to monsoon season) terrain could have contributed to increased number of accidents during this period. This is confirmed by the fact that more than $50 \%$ of the accidents were due to falls.

Even though more than $50 \%$ of the occupational accidents were due to falls (occupational falls or fall from trees) this is lesser compared to the previous study finding of $60.80 \%$ [8]. This decrease could be due to use of aluminum ladder instead of "Bamboo poles" for picking pepper and for shade lopping. The workers have to be trained in careful use of aluminum ladder to prevent electrocution.

There is an increase in the incidence of occupational cut injuries i.e. $24.2 \%$ as compared to the $13.6 \%$ in the study done in the year 2000 [8].

A study done in tea plantations at Sri Lanka reported fracture, sprain and dislocation as the most common type of injury followed by cuts and bruises [4]. In this study superficial injury including open (lacerated) wounds was the most common type of occupational injury followed by fractures.

Upper limb followed by lower limb were the most common site of injuries which is similar to the findings of the study done in tea plantations at Sri Lanka [4].

Although chemical fertilizers are used in the estates, there was no documentation of any hospitalization due to chemical exposure. This may be due to yearly health appraisal and laboratory investigations of labours, conducted by the plantation authorities for those involved in the use of agro-chemicals.

\section{Recommendations}

The type and cause of accident, site of injury and treatment given for all cases should be complete and proper documentation at the hospital, both for the record and legal purposes. The existing method of educating labours with regard to safety, benefits of following safety precautions and use of personal protective equipment's especially at the work place should be continued.

\section{References}

1. Plantations Labour Act, 1951. Worker's Right. URL: http:// www.doccentre.org/docsweb/LABOURLAWS/bare-acts/ plantation_act.htm. Last accessed 31st March 2012.

2. Coffee production in India. Available from URL: http:// en.wikipedia.org/wiki/Coffee_production_in_India. Cited on 8th April 2012.

3. History of tea in India. Available from URL: http://en.wikipedia.org/ wiki/History_of_tea_in_India. Cited on 8th April 2012.

4. Occupational Safety and Health in the Tea Plantation Sector in Sri Lanka, 1996-1997. ILO/EFC Plantation Safety and Health Monitoring Project; 1997. URL: http://www.ilo.org/public/english/ region/asro/bangkok/asiaosh/country/srilanka/sloshtea.htm. Last accessed 5th August 2011.

5. Main Statistics (annual) - Occupational injuries. URL: http:// laborsta.ilo.org/applv8/data/c8e.html. Last accessed 5th August 2011.

6. Takala J. Global estimates of fatal occupational accidents. Epidemiology. 1999;10:640-6.

7. Benavides FG, Delclos J, Benach J, Serra C. Occupational injury, A public health priority. Rev Esp. Salud Publica. 2006;80:553-65.

8. Loli N A, Biju P, Joseph B. A Profile of accidents reporting to a Rural Plantation Based Hospital. Indian Journal of Occupational and Environmental Medicine. July-Sept 2000; 4 (3): 125-127.

9. Report III, Statistics of occupational injuries. Sixteenth International Conference of Labour Statisticians, Geneva, 6-15 October 1998. International Labour Organization. ICLS/16/1998/III. International Labour Office, Geneva. Annex E. Classification according to type of injury. Pg. 56. URL: http://www.ilo.org/wcmsp5/groups/public/ @dgreports/@integration/@stat/documents/meetingdocument/ wcms_088373.pdf. Last cited on 30th August, 2011.

10. International Labour Organization. ICLS/16/1998/III. Report III, Statistics of occupational injuries. Sixteenth International Conference of Labour Statisticians. Geneva, 6-15 October 1998. International Labour Office, Geneva. Annex F. Classification according to part of body injured. Pg. 58. URL: http://www.ilo.org/ wcmsp5/groups/public/@dgreports/@integration/@stat/documents/ meetingdocument/wcms_088373.pdf. Last cited on 30th August, 2011. 